Journal of Clinical Investigation

Jol. 42, No. 10, 1963

\title{
URINARY EXCRETION OF NORADRENALINE AND ITS METABOLITES AT TEN-MINUTE INTERVALS AFTER INTRAVENOUS INJECTION OF $d l$-NORADRENALINE-2-C14 *
}

\author{
By McC. GOODALL AND LAWRENCE ROSEN \\ (From the Memorial Research Center and Hospital, The University of Tennessee, \\ Knoxville, Tenn.)
}

(Submitted for publication May 22, 1962; accepted June 20, 1963)

It is well-established that noradrenaline is the neurohormone of the sympathetic (adrenergic) nerves $(1-3)$ and is so released at the nerve endings. Further, it is known that after release, noradrenaline is rapidly inactivated and concomitantly, a number of metabolites are formed (4-7) (Figure 1) that biologically are relatively inactive. The rapidity, however, with which these metabolic products are formed in man and excreted in the urine is not precisely known.

In the earlier work on the metabolism of noradrenaline, urine collections were made at long intervals after infusion, i.e., at 1-hour intervals, for 24 hours $(5,7,8)$, and so gave limited information about events immediately after the infusion of noradrenaline. Therefore, these experiments were designed to give additional information about noradrenaline metabolites and their rates of formation and excretion as seen in the early periods after inactivation.

\section{METHODS}

Six women between 20 and 35 years old were injected intravenously with $9.5 \mu \mathrm{c}(80 \mu \mathrm{g})$ of $d l$-noradrenaline$2-\mathrm{C}^{14}$ (SA, $20 \mathrm{mc}$ per mmole). ${ }^{1}$ The labeled noradrenaline was mixed with $10 \mathrm{ml}$ of physiological saline and injected into the antecubital vein in 1 minute. Urine was collected from each subject via an indwelling Foley catheter 10 minutes after the beginning of the injection and every 10 minutes thereafter for a total of 70 minutes.

Separation of the urinary metabolites of noradrenaline, previously described by Goodall, Kirshner, and Rosen (5), has been modified as follows. A sample of urine containing 30,000 to $75,000 \mathrm{dpm}$ was placed on a $1-\times 4-\mathrm{cm}$ column of Amberlite IRC-50 (CG-50, type II), and the column was washed with $25 \mathrm{ml}$ of water. The combined effluent and wash were saved. The column was then eluted with $30 \mathrm{ml}$ of $0.5 \mathrm{~N}$ acetic acid. The radioactivity of a $0.1-\mathrm{ml}$ sample of the eluate was measured with a

* Work supported by U. S. Public Health Service grant A-5823.

1 Volk Radiochemical Company, Chicago, Ill.
Packard Tri-Carb liquid scintillation spectrometer. Another sample containing about 600 to $1,200 \mathrm{dpm}$ was evaporated to dryness and taken up in $1 \mathrm{ml}$ of water; the solution was chromatographed for 24 hours on Whatman 1 filter paper with $n$-butanol saturated with $1 \mathrm{~N} \mathrm{HCl}$ as the solvent. Such a method yields a clear separation of noradrenaline, 3-O-methylnoradrenaline (normetadrenaline), and an unknown. After drying, the paper was cut into 1-cm strips; each strip was placed in a 20-dram counting vial filled with scintillation liquid, and the radioactivity was measured with Tri-Carb liquid scintillation spectrometer. The percentage of radioactive noradrenaline, normetadrenaline, and the unknown substance in this sample was calculated, and when interpreted in terms of the total radioactivity recovered in the eluate of the Amberlite column, gave information about the total amount of radioactivity of each compound.

The effluent and wash from the Amberlite column were placed on a $1.0-\times 10.0-\mathrm{cm}$ Dowex 1-X2 (200-400 mesh) acetate column and fractionated as previously described (5). Briefly, ammonium acetate buffers at $\mathrm{pH} 4.8$ of varying molarity-i.e., $0.05,0.3,1.0$, and $3.0 \mathrm{M}$-were used to elute the acidic catabolites. The individual peaks were collected; in most cases, a $0.5-\mathrm{ml}$ sample was placed in each of two vials containing a liquid fluor and then assayed for radioactivity with the Tri-Carb liquid scintillation spectrometer. For some columns, however, the radioactivity of the peaks was assayed with a thin-window Geiger tube and corrected to infinite thinness by reference to a previously prepared absorption curve.

The radioactive material that passed through both the Amberlite and Dowex columns composed the "neutral fractions" and is referred to as the "Dowex effluent." The radioactivity in this fraction was also measured.

\section{RESULTS}

Amberlite eluate (basic metabolites). The data (Table I) show that of the total radioactivity recovered in the urine 10 minutes after injection, $28 \pm 3 \%$ is labeled noradrenaline; this amount rapidly decreased, so that after 20 minutes, the labeled noradrenaline represents only $10 \pm 3$ (SD) $\%$ of the total radioactivity and after 30 minutes, $5 \pm 1 \%$. The normetadrenaline and the unknown follow a pattern of excretion which is 


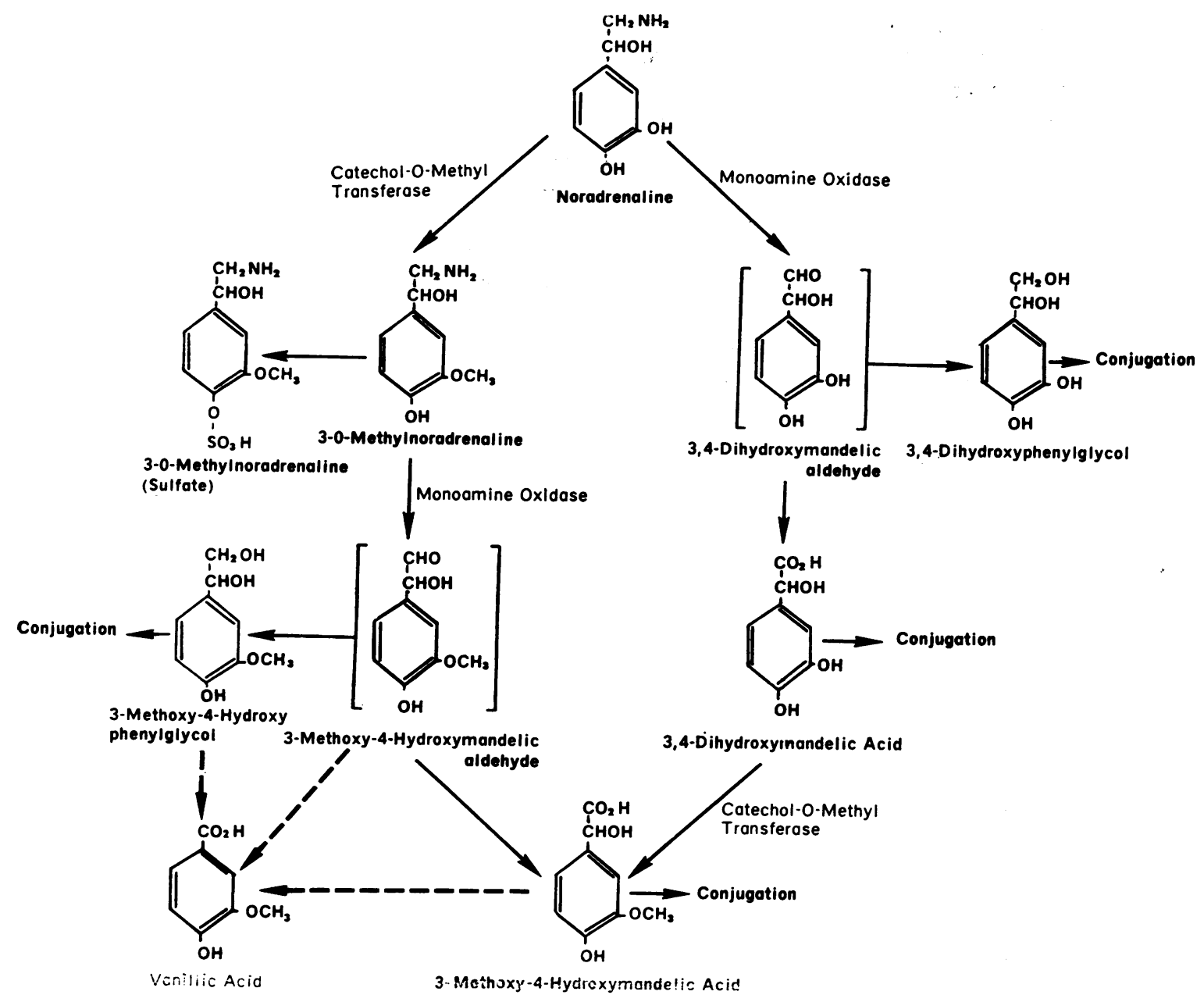

Fig. 1. Alternative Pathways for the Metabolism of nORAdrenaline.

similar to that of noradrenaline (Figures 2 and 3); as might be expected, however, the initial radioactivity recovered in these two fractions is not so high as that of the parent substance, noradrenaline (Table I).

The question naturally arises about what happens to the normetadrenaline once it is formed from noradrenaline. Current work (9) demonstrates that most of the normetadrenaline is converted to 3-methoxy-4-hydroxymandelic acid, especially in the early periods ( 0 to 30 minutes); however, there is a gradual and concomitant increase in the 3-O-methylnoradrenaline conjugate.

Dowex elution (acidic metabolites). $1.0 .05 \mathrm{M}$ Eluate. The metabolite eluted in this fraction is the 4-O-sulfate conjugate of normetadrenaline and is in effect a neutral conjugate that may be eluted from the Dowex column with water (7). The amount of the compound gradually increases so that during this first 10 minutes after injection, it represents only $5 \pm 2 \%$ of the total radioactivity, whereas by the end of the seventh 10-minute period (70 minutes), it represents $14 \pm 3 \%$ ( $\mathrm{Ta}-$ ble I, Figures 3 and 4). It has been previously shown that the amount of this metabolite continues to increase, so that in the 12- to 18-hour period after injection, it represents about $30 \%$ of the total radioactivity (5).

2. $0.3 \mathrm{M}$ Eluate. This fraction represents an unknown metabolite of noradrenaline, one distinguishable from the other metabolic products but not yet identified (Figure 4, Table I). The radioactivity in this fraction moves as a single compound when chromatographed either in $n$-butanol 
saturated with $1 \mathrm{~N} \mathrm{HCl}$, or in $4: 1: 1$ isopropanol; ammonia: water. It is not a major metabolite, since the total amount of radioactivity recovered represents only $2 \pm 1 \%$ in the initial 10 minutes and $6 \pm 2 \%$ in the last 10 minutes of a 70 -minute collection period. In a 24 -hour period, it represents only $10 \pm 2 \%$ of the recovered radioactivity (5).

3. 1.0 $M$ Eluate. The radioactivity recovered in this fraction is 3-methoxy-4-hydroxymandelic acid. This metabolite was first described by
Armstrong, McMillan, and Shaw $(t, 10)$ and represents the largest single metabolic product of noradrenaline (Table I, Figures 1-4). It is rapidly formed, representing $13 \pm 8 \%$ of the recovered radioactivity in the first 10 minutes and $48 \pm 11 \%$ by the end of the second 10 minutes (Table I), and reaches a maximum of about $50 \%$ 1 hour after injection and then decreases somewhat; for a 24-hour period, however, it represents about one-third of the total radioactivity (5).

4. 3.0 $M$ Eluate. This fraction represents a

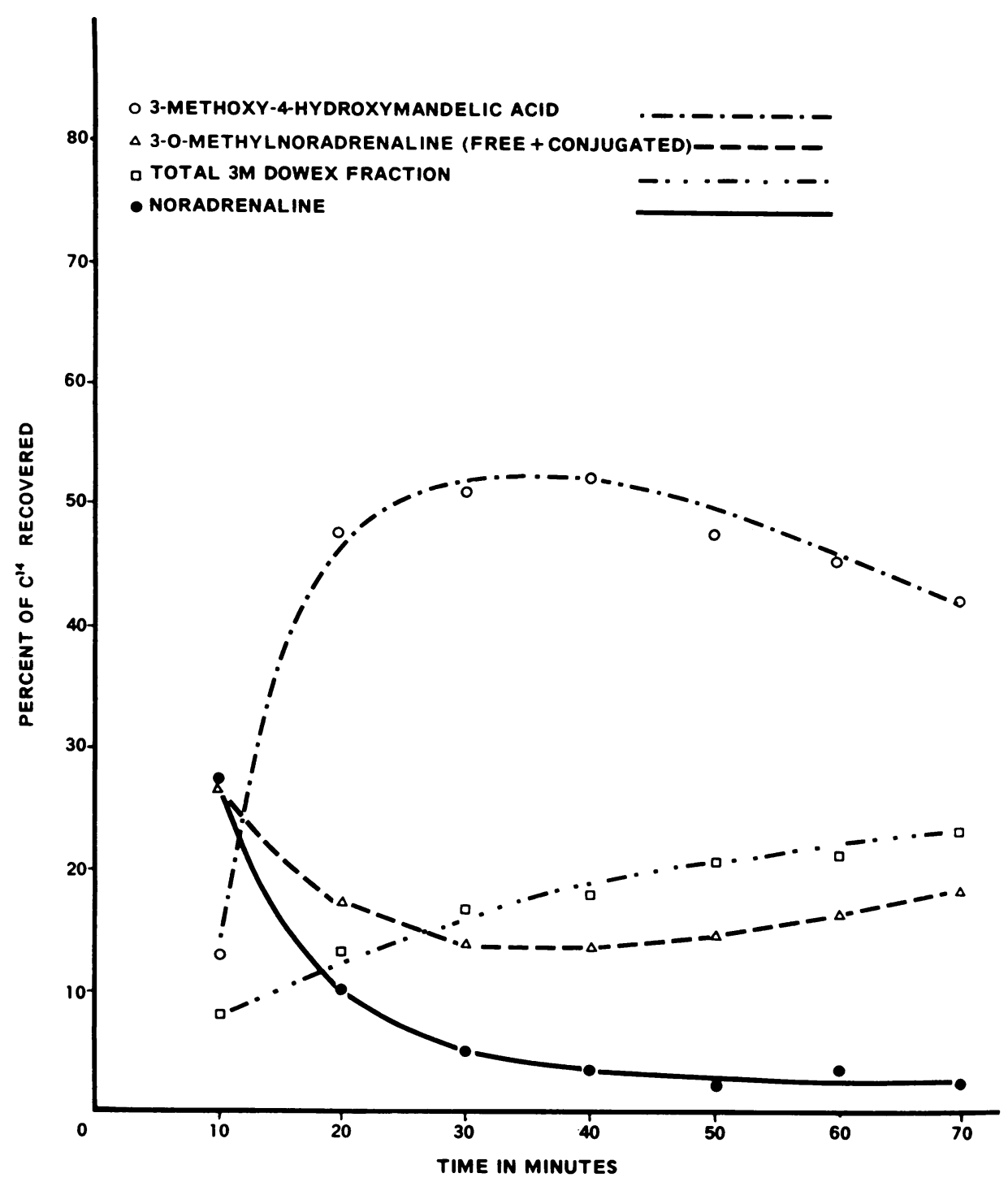

Fig. 2. A comparative excretion pattern Showing the gradual decrease iN radioACTIVE NORADRENALINE AND THE CONCOMITANT RISE IN SEVERAL OF THE RADIOACTINE NORADRENALINE METABOLITES AFTER IV INJECTION OF NORADRENALINE-2-C14. 


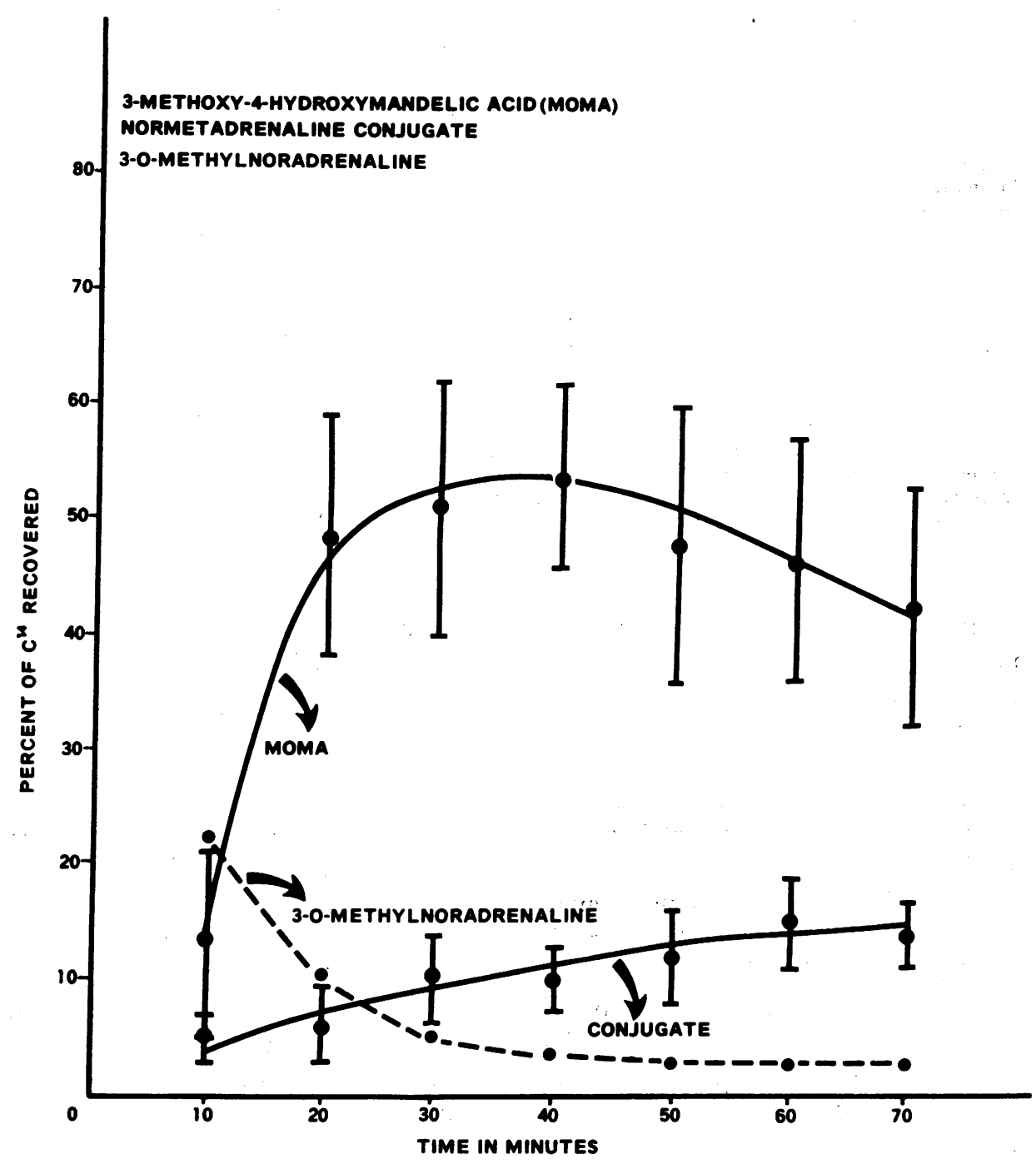

Fig. 3. A COMPARATIVE EXCRETION PATTERN SHOWING THE DECLINE OF RADIOACTIVE 3-OMETHYLNORADRENALINE AND THE CONCOMITANT RISE OF RADIOACTIVE 3-METHOXY-4-HYDROXYMANDELIC ACID AND 3-O-METHYLNORADRENALINE CONJUGATE AFTER IV INJECTION OF NORADRENALINE-2-C14.

composite of several noradrenaline metabolites that are difficult to separate. For this reason, they have been grouped together under the single heading of " $3.0 \mathrm{M}$ eluate" (Table I, Figures 2 and 4 ). The metabolites present in this fraction can be separated into three subfractions, the first containing 3,4-dihydroxymandelic acid, vanillic acid (11), and at least one other lesser compound; the second contains protocatechuic acid, the sulfate of 3-methoxy-4-hydroxyphenylglycol, and presumably conjugates of mandelic acid and 3,4-dihydroxyphenylglycol; and the third contains less than $4 \%$ of the recovered radioactivity, and its compounds have not yet been evaluated.

That 3,4-dihydroxymandelic acid represents approximately 10 to $15 \%$ of the total radioactivity recovered in the $3.0 \mathrm{M}$ eluate fraction gives some indication of the role of oxidative deamination in the initial inactivation of noradrenaline (Figure 1). Recently, Crout, Creveling, and Udenfriend (12) showed in the rat that monoamine oxidase activity (oxidative deamination) was 3.6 and 5 times greater than catechol-O-methyltransferase activity in the brain and heart, respectively. 
TABLE I

Excretion pattern of noradrenaline and metabolites at 10-minute intervals during a 70-minute postinjection period after injection*

\begin{tabular}{|c|c|c|c|c|c|c|c|c|c|c|}
\hline \multirow{2}{*}{$\begin{array}{l}\text { Collection } \\
\text { time } \\
\text { after in- } \\
\text { fusion }\end{array}$} & \multirow[b]{2}{*}{$\begin{array}{l}\% \text { of infused } \\
\text { dose recovered }\end{array}$} & \multicolumn{4}{|c|}{ Amberlite fractions } & \multicolumn{4}{|c|}{ Dowex fractions } & \multirow[b]{2}{*}{$\begin{array}{l}\text { Dowex } \\
\text { effluent } 2\end{array}$} \\
\hline & & $\begin{array}{c}\text { Amberlite } \\
\text { eluate }\end{array}$ & Nor. & Normet. & Unk. & $\begin{array}{l}\text { Normet. } \\
\text { conjug. }\end{array}$ & Unk. & MOMA & $3 \mathrm{MI}$ & \\
\hline $\begin{array}{c}\min \\
0-10 \\
10-20 \\
20-30 \\
30-40 \\
40-50 \\
50-60 \\
60-70\end{array}$ & $\begin{array}{c}\% \\
7.9 \pm 1.7 \\
5.1 \pm 0.7 \\
3.8 \pm 0.6 \\
3.0 \pm 0.4 \\
2.9 \pm 0.3 \\
2.3 \pm 0.3 \\
2.5 \pm 0.2\end{array}$ & $\begin{array}{c}\% \\
69 \pm 10 \\
25 \pm 7 \\
12 \pm 3 \\
8 \pm 2 \\
6 \pm 2 \\
7 \pm 2 \\
6 \pm 2\end{array}$ & $\begin{array}{c}\% \\
28 \pm 3 \\
10 \pm 3 \\
5 \pm 1 \\
4 \pm 1 \\
2 \pm 1 \\
3 \pm 1 \\
2 \pm 1\end{array}$ & $\begin{array}{c}\% \\
22 \pm 6 \\
11 \pm 4 \\
5 \pm 1 \\
4 \pm 1 \\
3 \pm 1 \\
3 \pm 1 \\
3 \pm 1\end{array}$ & $\begin{array}{c}\% \\
12 \pm 3 \\
3 \pm 1 \\
1 \pm 1 \\
\text { trace } \\
\text { trace } \\
\text { trace } \\
\text { trace }\end{array}$ & $\begin{array}{c}\% \\
5 \pm 2 \\
6 \pm 3 \\
10 \pm 4 \\
10 \pm 3 \\
12 \pm 4 \\
15 \pm 4 \\
14 \pm 3\end{array}$ & $\begin{array}{c}\% \\
2 \pm 1 \\
2 \pm 1 \\
3 \pm 1 \\
4 \pm 2 \\
5 \pm 2 \\
7 \pm 2 \\
6 \pm 2\end{array}$ & $\begin{array}{c}\% \\
13 \pm 8 \\
48 \pm 11 \\
51 \pm 11 \\
53 \pm 7 \\
47 \pm 9 \\
46 \pm 10 \\
43 \pm 10\end{array}$ & $\begin{array}{c}5 \\
8 \pm 5 \\
14 \pm 3 \\
17 \pm 3 \\
18 \pm 3 \\
21 \pm 4 \\
21 \pm 3 \\
23 \pm 7\end{array}$ & $\begin{array}{c}\% \\
4 \pm 2 \\
3 \pm 1 \\
3 \pm 1 \\
4 \pm 1 \\
4 \pm 2 \\
4 \pm 2 \\
4 \pm 1\end{array}$ \\
\hline
\end{tabular}

* All data are expressed as percentage of recovered radioactivity \pm SD. Nor., noradrenaline; normet., normetadrenaline, 3-O-methylnoradrenaline; Unk., unknown; normet. conjug., 3-O-methylnoradrenaline conjugate; MOMA, 3-methoxy-4-hydroxymandelic acid; $3 \mathrm{M}$ includes 3,4-dihydroxymandelic acid, vanillic acid, protocatechuic acid, sulfate of 3-methoxy-4-hydroxyphenylglycol, and probably conjugates of mandelic acid and 3,4-dihydroxyphenylglycol.

The total radioactivity recovered in the $3.0 \mathrm{M}$ fraction represents $8 \pm 5 \%$ in the first 10 minutes after injection and rapidly increases, so that by the 60- to 70-minute collection period it represents $23 \pm 7 \%$ (Table I). The average for 24 hours is $24 \pm 4 \%$ (5).

Dowex effluent (neutral metabolites). This is a relatively unimportant fraction in that it represents only 3 to $5 \%$ of the total radioactivity recovered from the urine (Table I). It does not change greatly from the first to the last collection period, i.e., from $4 \pm 2 \%$ in the first 10 minutes to $4 \pm 1 \%$ in 24 hours (5). This material is distributed among two or three fractions as determined by chromatography in $n$-butanol saturated with $\mathrm{N}$ $\mathrm{HCl}$. More than $50 \%$ of the total neutral fraction exhibits an $R_{f}$ value less than 0.1 , and probably contains the glucuronide of normetadrenaline and possibly that of noradrenaline. The fastermoving material $\left(R_{f}, 0.50\right.$ to 0.70$)$, which sometimes separates into two peaks, apparently contains 3-methoxy-4-hydroxyphenylglycol (13) and 3,4-dihydroxyphenylglycol (14).

Whereas Table I represents the percentage of recovered radioactivity of each metabolite, it does not give absolute quantities. Therefore, Table II has been included to show these absolute quantities as they compare with one another.

Analysis of the results in terms of the absolute amount of the basic compounds (Amberlite eluate) excreted shows an interesting phenomenon. In the first 10-minute collection period, these compounds, including the sulfate of 3-O-methylnoradrenaline, account for $0.56 \mu \mathrm{c}$; this value declines to $0.05 \mu \mathrm{c}$ in the 30 - to 40 -minute collection period and is maintained at this level throughout the 70-

TABLE II

Excretion pattern of noradrenaline and noradrenaline metabolites at 10-minute intervals during a 70-minute period after infusion*

\begin{tabular}{|c|c|c|c|c|c|c|c|c|c|c|}
\hline \multirow{2}{*}{$\begin{array}{l}\text { Collection } \\
\text { time } \\
\text { after in- } \\
\text { fusion }\end{array}$} & \multirow{2}{*}{$\begin{array}{c}\text { Total } \\
\text { C14 } \\
\text { recovered }\end{array}$} & \multicolumn{4}{|c|}{ Amberlite fractions } & \multicolumn{4}{|c|}{ Dowex fractions } & \multirow[b]{2}{*}{$\begin{array}{l}\text { Dowex } \\
\text { Effluent } 2\end{array}$} \\
\hline & & $\begin{array}{c}\text { Amberlite } \\
\text { eluate }\end{array}$ & Nor. & Normet. & Unk. & $\begin{array}{l}\text { Normet. } \\
\text { conjug. }\end{array}$ & Unk. & MOMA & $3 \mathrm{M}$ & \\
\hline $\min$ & $\mu c$ & $\mu c$ & $\mu c$ & $\mu c$ & $\mu c$ & $\mu c$ & $\mu c$ & $\mu c$ & $\mu c$ & $\mu c$ \\
\hline $0-10$ & 0.75 & 0.52 & 0.21 & 0.17 & 0.09 & 0.038 & 0.015 & 0.10 & 0.06 & 0.03 \\
\hline $10-20$ & 0.48 & 0.12 & 0.05 & 0.05 & 0.01 & 0.029 & 0.01 & 0.23 & 0.07 & 0.01 \\
\hline $20-30$ & 0.36 & 0.04 & 0.02 & 0.02 & & 0.036 & 0.01 & 0.18 & 0.06 & 0.01 \\
\hline $30-40$ & 0.29 & 0.02 & 0.01 & 0.01 & & 0.029 & 0.01 & 0.15 & 0.05 & 0.01 \\
\hline $40-50$ & 0.28 & 0.02 & 0.006 & 0.008 & & 0.033 & 0.01 & 0.13 & 0.06 & 0.01 \\
\hline $50-60$ & 0.22 & 0.015 & 0.007 & 0.007 & & 0.033 & 0.015 & 0.10 & 0.05 & 0.01 \\
\hline $60-70$ & 0.24 & 0.014 & 0.005 & 0.007 & & 0.033 & 0.014 & 0.10 & 0.05 & 0.01 \\
\hline
\end{tabular}

* Data were compiled from the data of Table I. E.g., in the 10 - to 20 -minute period, $5.1 \%$ of the infused dose (9.5 $\mu$ c) was recovered $=0.051 \times 9.5=0.48 \mu \mathrm{c} ; \mathrm{MOMA}$ accounted for $48 \%$ of the recovered $\mathrm{C}^{14}$ in this interval; $\mu \mathrm{c}$ MOMA $=0.48 \times 0.48=0.23$. 


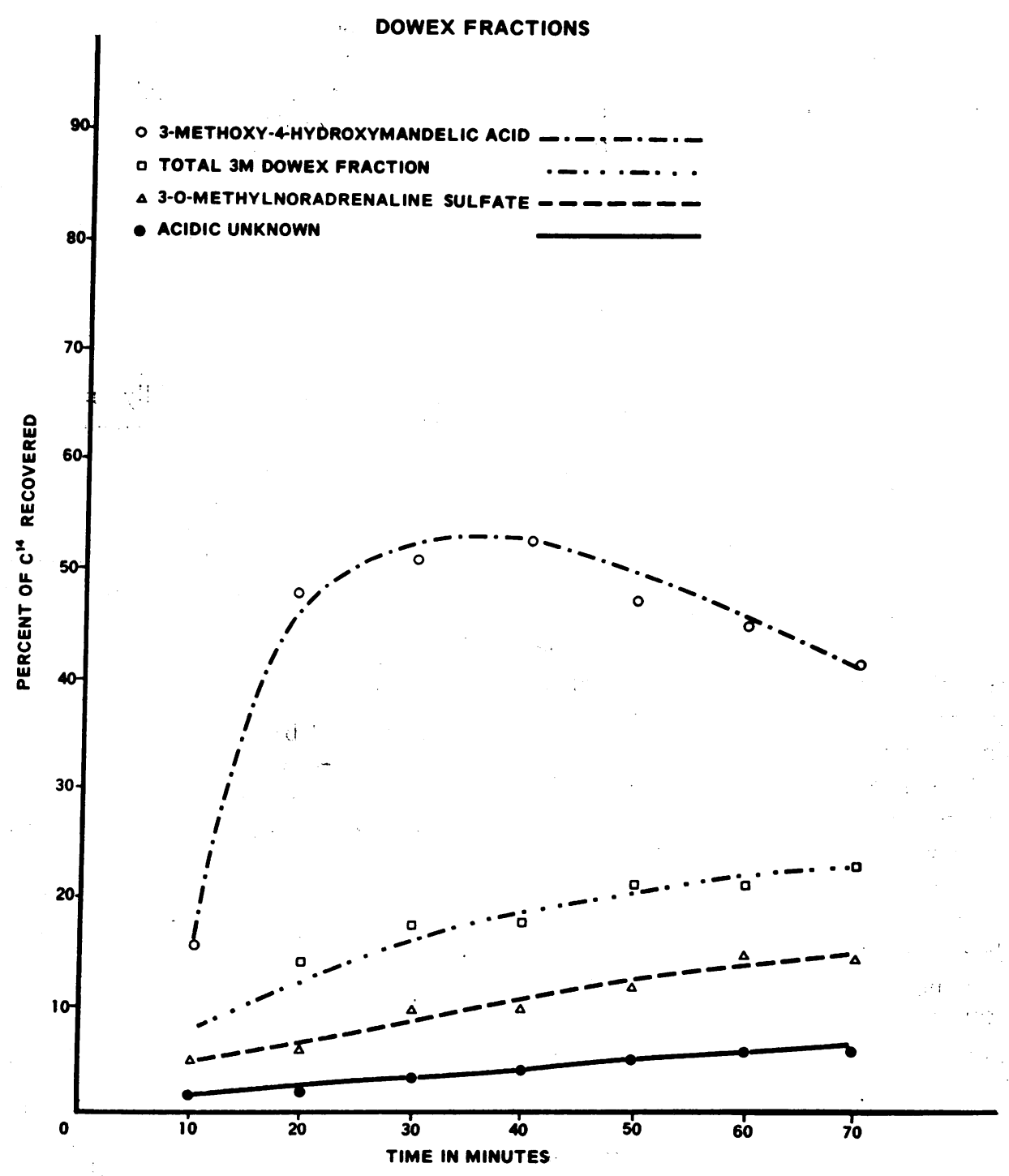

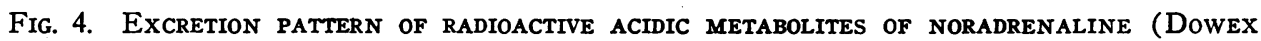
FRACTIONS) AFTER IV INJECTION OF NORADRENALINE-2-C14.

minute collection period. Although the percentage of the radioactivity, which is recovered as a sulfate, increases with time, this conjugate is actually excreted at a fairly constant rate, $0.03 \mu \mathrm{c}$ in each collection period (Table II).

With respect to the neutral and acidic metabolites, two important findings should be emphasized. The first of these is the very rapid increase in 3-methoxy-4-hydroxymandelic acid, both in the percentage of recovered radioactivity and in actual amount. The data show an increase from 13 $\pm 8 \%$ or $0.10 \mu \mathrm{c}$ in the first collection period to $48 \pm 11 \%$ or $0.23 \mu \mathrm{c}$ in the 10 - to 20 -minute period (Tables I and II). The percentage of radioactivity recovered as 3-methoxy-4-hydroxymandelic acid further increases in subsequent periods; however, the actual amount of 3-methoxy-4-hydroxymandelic acid decreases steadily to $0.10 \mu \mathrm{c}$ in the 50- to 60-minute period. Second, the other acidic and the neutral metabolites are excreted in fairly constant amounts during each 10-minute period (Table II). 


\section{DISCUSSION}

Although an iv injection of noradrenaline cannot be extrapolated in the precise terms of the normal release of noradrenaline from the adrenergic nerve endings, there are nevertheless some distinct similarities. For example, these experiments could be closely correlated to the release of noradrenaline from a noradrenaline-producing pheochromocytoma, which, as is known, can release into the vascular system very large quantities of noradrenaline (15-19), or in paroxysms, quantities far exceeding the $80 \mu \mathrm{g}$ per minute used in these experiments. Furthermore, even normal subjects under specific stressful conditions (2024) release over short intervals quantities of noradrenaline that could approximate that used in these experiments. The most important difference between an injection of noradrenaline and the normal release of this neurohormone, however, lies in those unknown physiologic and metabolic processes occurring at the releasing site; whereas noradrenaline is normally released in small quantities at multiple sites, in these experiments the noradrenaline was derived from a single site in the antecubital vein. Despite this important difference, there are even other similarities between the use of exogenous and the release of endogenous noradrenaline. For example, 20 to $60 \mu \mathrm{g}$ of noradrenaline normally occurs in the 24-hour urine $(20,22,25,26)$, and under severe stressful conditions, up to $485 \mu \mathrm{g}$ per 24 hours (20), which clearly indicates that a certain amount of the noradrenaline normally released from the adrenergic nerve endings is not metabolized at the releasing site or elsewhere, but is transmitted by the blood stream and ultimately cleared by the kidney. Von Euler and Luft (27) showed that after an infusion of noradrenaline in the human, only 1.5 to $3.3 \%$ of the infused dose could be accounted for in the urine; from their experiments, it was inferred that normally some 0.5 to $1 \% l$-noradrenaline per minute reached the general circulation. Furthermore, it is well-known that with an infusion of noradrenaline, certain compensatory mechanisms come into play that depress the release of endogenous noradrenaline; this implies that at least some of the exogenous noradrenaline is handled like the endogenous.

Although our study does not give precise in- formation about events the moment after release of noradrenaline, it does give some information about noradrenaline metabolism, and especially about the probable metabolic pattern of noradrenaline during the first few minutes after its release; that is, from the information plotted in Figures 2, 3, and 4, one can, by extending the curve from the 10-minute point to the time of injection, acquire some insight into probable events shortly after the release of noradrenaline.

From these results, it is apparent that the noradrenaline is rather rapidly metabolized, i.e., $27.5 \%$ of radioactivity is recovered in the urine within 70 minutes. Why the metabolic products continue to be excreted over a long time is not entirely clear; it would seem, however, that the metabolites diffuse into the tissue spaces and cells from which they gradually return to the general circulation and are excreted by the kidneys. Further, it has been shown that when labeled adrenaline was injected into a cat, many of the metabolic products could be accounted for in the liver, kidney, and heart, and presumably other sites (14). The possible role of noradrenaline binding was first established many years ago (28-34), and more recently, also the binding of the metabolites $(14,35-39)$, but the extent and methods of binding probably vary from one animal species to another (40) and certainly from one tissue to another; therefore, the extrapolation of such results to man should be done with extreme caution.

It is, however, reasonable to conclude that noradrenaline metabolites accumulate in the tissues and tissue spaces, and over a period of 24 to 96 hours, are slowly released into the general circulation and excreted by the kidney, as previous work certainly seems to indicate (5). However, some of the metabolites initially formed (e.g., 3,4-dihydroxymandelic aldehyde, 3,4-dihydroxymandelic acid) could undergo changes before storage or excretion, and therefore might very well differ in quantity and type from the final metabolites found in either the tissue or urine.

The major radioactive compound found in the urine in the first 10 minutes after injection of noradrenaline is noradrenaline itself; there is, however, a rapid decline in the noradrenaline. Although initially not so high as noradrenaline, there is a similar decline in the 3-O-methylnoradrenaline and the basic unknown; at the same 
time, there is an increase in the 3-O-methylnoradrenaline conjugate (Figures 3 and 4 ). This conjugate, which is a sulfate, increases from about $5 \%$ in the first 10 mintes to $15 \%$ by 60 minutes. It has previously been shown that the amount of this metabolite continues to increase so that by the 12- to 18 -hour period, it represents about $33 \%$ of the total radioactivity (5). That such a large percentage of the radioactivity is ultimately found in this conjugate gives some indication of the importance of O-methylation and conjugation as a metabolic pathway for the metabolism of noradrenaline in man (Figure 1, Table I).

This brings up the question of $\mathrm{O}$-methylation and oxidative deamination as a means of inactivating noradrenaline. In the past, some investigators have placed great emphasis upon O-methylation $(6,41)$ as the only, or certainly the principal, mechanism for the initial inactivation of catechol amines; in view of present evidence, however, such emphasis is unwarranted, since oxidative deamination also occurs in the initial inactivation of noradrenaline. From the metabolic products formed, it is clear that both oxidative deamination and O-methylation occur in the initial inactivation, and that these probably occur simultaneously but at different rates, depending upon the site of inactivation. Certainly the results described here and the recent work of Crout and associates (12) and Iisalo (42) support such a concept. Furthermore, other enzyme systems, although not yet elucidated, are probably involved in the inactivation of noradrenaline, as now seems particularly evident in the understanding of noradrenaline metabolism in thyrotoxicosis (43-51).

Injected noradrenaline is not distributed among all tissues in precisely the same manner as noradrenaline normally released from the sympathetic nerve endings. Also, different tissues vary in their capacity for metabolizing, binding, and storing noradrenaline and its metabolites. The radioactivity found in the urine as noradrenaline and noradrenaline metabolites therefore reflects metabolism of the body as a whole rather than that of an individual tissue. To state this differently, our data may not accurately reflect the relative quantitative importance of the various metabolic pathways in the disposition of noradrenaline, or, the pattern of urinary excretion of label may not be an accurate quantitative guide to the actual pattern to the metabolism of injected radioactive noradrenaline.

Despite the precipitous drop in the amount of radioactive noradrenaline found in the urine immediately after infusion (Tables I and II, Figure 2), this compound does not disappear from the urine until 6 to 12 hours after infusion and may even persist in trace amounts for as long as 24 hours (5). That small amounts of noradrenaline continue to appear in the urine for long periods after an infusion clearly demonstrates that not all of the noradrenaline is immediately metabolized, and that at least some of it must be bound, or must be stored as free noradrenaline $(34,36$, 52) for subsequent release and metabolism.

Although the early experiments on noradrenaline, with their long collection periods after infusion, gave information on the metabolites of noradrenaline in the human urine, they told very little about the rate of metabolite formation, especially in the early periods, and this latter information is very important for the understanding of some of the clinical entities directly or indirectly related to an aberration in noradrenaline metabolism. For example, no significant difference is noted between the metabolism of noradrenaline in normal subjects and that in patients with orthostatic hypotension (53) and hyperthyroidism (51) unless the metabolism of noradrenaline is followed at short intervals within the first hour after release.

\section{SUM MARY}

1. Normal young women were injected intravenously with $9.5 \mu \mathrm{c}(80 \mu \mathrm{g})$ of $d l$-noradrenaline-2$\mathrm{C}^{14}$ (SA, $20 \mathrm{mc}$ per millimole). The labeled noradrenaline was mixed with $10 \mathrm{ml}$ of physiological saline and injected into the antecubital vein in 1 minute. The urine was collected via an indwelling catheter at 10 -minute intervals for a total of 70 minutes.

2. The urinary metabolites of noradrenaline were separated by a combination of column fractionation (ion exchange resin, Amberlite IRC-50 and Dowex-1) and paper chromatography. The radioactivity of each metabolite was measured with a liquid scintillation spectrometer.

3. Noradrenaline and the basic metabolites, normetadrenaline and an unknown, were retained and eluted from Amberlite IRC-50. The acidic me- 
tabolites, normetadrenaline conjugate, 3-methoxy4-hydroxymandelic acid, 3,4-dihydroxymandelic acid, vanillic acid, protocatechuic acid, and sulfate of 3-methoxy-4-hydroxyphenylglycol, are retained by Dowex-1; other lesser metabolites, probably conjugates of the mandelic acids, conjugate of 3,4dihydroxyphenylglycol, and several unknown compounds were also retained and eluted from Dowex-1. The neutral metabolites passed through both columns, and seemed to be the glucuronide of normetadrenaline and noradrenaline, 3-methoxy-4hydroxyphenylglycol, and 3,4-dihydroxyphenylglycol.

4. Of the total radioactivity recovered in the urine 10 minutes after injection, $28 \pm 3 \%$ was labeled noradrenaline; this rapidly decreased so that after 20 minutes, it represented only $10 \pm 3 \%$, after 30 minutes, $5 \pm 1 \%$, and after 70 minutes, $2 \pm 1 \%$. Trace amounts, however, were found in the urine 6 to 18 hours after infusion. The normetadrenaline and the acidic unknown followed a declining pattern of excretion similar to that of noradrenaline.

5. As the percentage of radioactive noradrenaline decreased, there was a concomitant rise in most of the acidic metabolites, particularly in 3-methoxy-4-hydroxymandelic acid and normetadrenaline conjugate. The percentage of radioactivity in the 3-methoxy-4-hydroxymandelic acid rose from $13 \pm 8 \%$ in the first 10 minutes to 53 $\pm 7 \%$ in the 30 - to 40 -minute period, and then decreased slowly to $43 \pm 10 \%$ in the 60 - to 70 minute period. In the normetadrenaline conjugate, the percentage gradually rose from $5 \pm 2 \%$ in the first 10 minutes to $14 \pm 3 \%$ in the 60 - to 70 -minute period; the absolute quantities of this conjugate remained relatively the same for each collection period. The acidic unknown and the metabolites constituting the $3 \mathrm{M}$ fraction also showed a gradual but persistent increase in the percentage of radioactivity from the first to the last 10-minute collection.

6. The neutral fraction is relatively unimportant in that it represents only 3 to $5 \%$ of the total radioactivity recovered, and varies little from the first to the last collection period.

7. Despite the obvious dissimilarity between the release of exogenous and endogenous noradrenaline, such experiments as these give an insight into the metabolism of the naturally occurring nor- adrenaline. Furthermore, our results and those of others clearly show both oxidative deamination and O-methylation to occur in the metabolism of noradrenaline; probably, they occur simultaneously, but at different rates, depending upon the tissue involved.

8. That small amounts of noradrenaline continue to appear in the urine for 6 to 18 hours after an infusion clearly demonstrates that not all of the noradrenaline is immediately metabolized, and at least some of it must be bound, stored as free noradrenaline for subsequent release and metabolism, or both.

9. Although the early experiments on noradrenaline, with their long collection periods after infusion, gave information on the metabolites of noradrenaline in human urine, they gave little on the rate of metabolite formation, especially in the early period, and this information is very important for the understanding of some of the clinical entities directly or indirectly related to an aberration in noradrenaline metabolism.

\section{REFERENCES}

1. Von Euler, U. S. A specific sympathomimetic ergone in adrenergic nerve fibres (sympathin) and its relation to adrenaline and noradrenaline. Acta physiol. scand. 1946, 12, 73.

2. Goodall, McC., and N. Kirshner. Biosynthesis of epinephrine and norepinephrine by sympathetic nerves and ganglia. Circulation 1958, 17, 366.

3. Von Euler, U. S., and F. Lishajko. Noradrenaline release from isolated nerve granules. Acta physiol. scand. 1961, 51, 193.

4. Armstrong, M. D., A. McMillan, and K. N. F. Shaw. 3-Methoxy-4-hydroxy- $d$-mandelic acid, a urinary metabolite of norepinephrine. Biochim. biophys. Acta (Amst.) 1957, 25, 422.

5. Goodall, McC., N. Kirshner, and L. Rosen. Metabolism of noradrenaline in the human. J. clin. Invest. 1959, 38, 707.

6. Axelrod, J. Metabolism of epinephrine and other sympathomimetic amines. Physiol. Rev. 1959, 39, 751.

7. Goodall, McC. Metabolic products of adrenaline and noradrenaline in human urine. Pharmacol. Rev. 1959, 11, 416.

8. Rosen, L., and McC. Goodall. Effect of iproniazid on metabolism of noradrenaline in man. Amer. J. Physiol. 1962, 202, 883.

9. Goodall, McC., and L. Rosen. 3-O-methylnoradrenaline metabolism in the human. To be published.

10. Armstrong, M. D., and A. McMillan. Identification of a major urinary metabolite of norepinephrine. Fed. Proc. 1957, 16, 146. 
11. Rosen, L., and McC. Goodall. The identification of vanillic acid as a catabolite of noradrenaline metabolism in the human. Proc. Soc. exp. Biol. (N. Y.) 1962, 110, 767.

12. Crout, J. R., C. R. Creveling, and S. Udenfriend. Norepinephrine metabolism in rat brain and heart. J. Pharmacol. exp. Ther. 1961, 132, 269.

13. Axelrod, J., I. J. Kopin, and J. D. Mann. 3-Methoxy4-hydroxyphenylglycol sulfate, a new metabolite of epinephrine and norepinephrine. Biochim. biophys. Acta (Amst.) 1959, 36, 576.

14. De Schaepdryver, A. F., and N. Kirshner. Metabolism of adrenaline after blockade of monoamine oxidase and catechol-O-methyltransferase. Science 1961, 133, 586.

15. Von Euler, U. S., and G. Ström. Present status of diagnosis and treatment of pheochromocytoma. Circulation 1957, 15, 5.

16. Goodall, $\mathrm{McC}$., and C. Stone. Adrenaline and noradrenaline producing tumors of the adrenal medulla and sympathetic nerves. Ann. Surg. 1960, 151, 391.

17. West, G. B., and N. R. W. Taylor. Studies in phaeochromocytoma. III. The excretion of noradrenaline in the urine of cases of hypertension and its value in the diagnosis of phaeochromocytoma. Glas. med. J. 1955, 36, 123.

18. Crout, J. R., and A. Sjoerdsma. Catecholamines in the localization of pheochromocytoma. Circulation 1960, 22, 516.

19. Roth, G. M., E. V. Flock, W. F. Kvale, J. M. Waugh, and J. Ogg. Pharmacologic and chemical tests as an aid in the diagnosis of pheochromocytoma. Cirulation 1960, 21, 769.

20. Goodall, McC., C. Stone, and B. W. Haynes, Jr. Urinary output of adrenaline and noradrenaline in severe thermal burns. Ann. Surg. 1957, 145, 479.

21. Von Euler, U. S., and S. Hellner. Noradrenaline excretion in muscular work. Acta physiol. scand. 1952, 26, 183.

22. Goodall, McC., and M. Bogdonoff. Essential hypertension with an elevated noradrenaline excretion. Amer. Heart J. 1961, 61, 640.

23. Goodall, McC. Sympathoadrenal response to gravitational stress. J. clin. Invest. 1962, 41, 197.

24. Von Euler, U. S. Noradrenaline: Chemistry, Physiology, Pharmacology, and Clinical Aspects. Springfield, Ill., Charles C Thomas, 1956.

25. Von Euler, U. S., and S. Hellner. Excretion of noradrenaline, adrenaline, and hydroxytyramine in urine. Acta physiol. scand. 1951, 22, 161.

26. Von Euler, U. S., S. Hellner, and A. Purkhold. Excretion of noradrenaline in urine in hypertension. Scand. J. clin. Lab. Invest. 1954, 6, 54.

27. Von Euler, U. S., and R. Luft. Noradrenaline output in urine after infusion in man. Brit. J. Pharmacol. 1951, 6, 286.

28. Richter, D., and F. C. MacIntosh. Adrenaline ester. Amer. J. Physiol. 1941, 135, 1.
29. Brante, G. Studies on lipids in the nervous system. Acta physiol. scand. 1949, 18, suppl. 13.

30. Norlander, O. Ether soluble compounds of adrenaline and noradrenaline with lecithin. Acta physiol. scand. 1950, 21, 325.

31. Clark, W. G., R. I. Akawie, R. S. Pogrund, and T. A. Geissman. Conjugation of epinephrine in vivo. J. Pharmacol. exp. Ther. 1951, 101, 6.

32. Augustinsson, K. B. Reaction of organophosphorus compounds with dihydroxyphenyl derivatives. Acta chem. scand. 1952, 6, 959.

33. Hillarp, N. A., and B. Nilson. Some quantitative analyses of sympathomimetic amine containing granules in adrenal medullary cell. Acta physiol. scand. 1954, 32, 11.

34. Raab, W., and W. Gigee. Specific avidity of the heart muscle to absorb and store epinephrine and norepinephrine. Circulat. Res. 1955, 3, 553.

35. Kirshner, N. The metabolism of $\left[{ }^{14} \mathrm{C}\right]( \pm)$ - adrenaline in the cat. Adrenergic Mechanisms. London, Ciba Foundation Symposium, 1960.

36. Whitby, L. G., J. Axelrod, and H. Weil-Malherbe. The fate of $\mathrm{H}^{3}$-norepinephrine in animals. J. Pharmacol. exp. Ther. 1961, 132, 193.

37. Hertting, G., J. Axelrod, and L. G. Whitby. Effect of drugs on the uptake and metabolism of $\mathrm{H}^{3}$ norepinephrine. J. Pharmacol. exp. Ther. 1961, $134,146$.

38. Dirscherl, W., H. Thomas, and H. Schriefers. Vanillinsäure als Endprodukt des Abbaues von Adrenalin und Noradrenalin. Acta Endocr. (Kbh.) 1962, $39,385$.

39. Imhof, P., F. Hediger, and H. Kaser. Uber Kreislaufregulationsstorungen und Veranderungen der 3-Methoxy-4-hydroxymandelsaure-ausscheidung im Urin nach traumatischer Querschnittlasion des Ruckenmarks. Helv. med. Acta 1962, 29, 183.

40. Shideman, F. E., and N. D. Goldberg. A species difference in metabolism of myocardial catecholamines. Biochem. Pharmacol. 1961, 8, 65.

41. LaBrosse, E. H., J. Axelrod, and S. S. Kety. O-methylation, the principal route of metabolism of epinephrine in man. Science 1958, 128, 593.

42. Iisalo, E. Enzyme action on noradrenaline and adrenaline. Acta pharmacol. (Kbh.) 1962, 19, suppl. 1.

43. Goodall, McC. Studies of adrenaline and noradrenaline in mammalian heart and suprarenals. Acta physiol. scand. 1951, 24, suppl. 85.

44. Schneckloth, R. E., G. S. Kurland, and A. S. Freedberg. Effect of variation in thyroid function on the pressor response to norepinephrine in man. Metabolism 1953, 2, 546.

45. Brewster, W. R., Jr., J. P. Isaacs, P. F. Osgood, and T. L. King. The hemodynamic and metabolic interrelationships in the activity of epinephrine, norepinephrine and the thyroid hormones. Circulation 1956, 13, 1. 
46. Söderberg, U. Temporal characteristics of thyroid activity. Physiol. Rev. 1959, 39, 777.

47. Zile, M., and H. A. Lardy. Monoamine oxidase activity in liver of thyroid-fed rats. Arch. Biochem. 1959, 82, 411.

48. D'Iorio, A., and J. Leduc. The influence of thyroxine on the O-methylation of catechols. Arch. Biochem. 1960, 87, 224.

49. Ishida, N. Metabolism of catecholamines in hyperand hypo-thyroid patients. Tohoku J. exp. Med. 1962, 78, 228.
50. Spinks, A., and J. H. Burn. Thyroid activity and amine oxidase in the liver. Brit. J. Pharmacol. 1952, 7, 93.

51. Goodall, McC., H. Alton, and L. Rosen. Noradrenaline metabolism in hyperthyroidism. Fed. Proc. 1962, 21, 215.

52. Burn, G. P., and J. H. Burn. Uptake of labelled noradrenaline by isolated atria. Brit. J. Pharmacol. 1961, 16, 344.

53. Goodall, McC., H. Alton, and W. Harlan. Metabolism of noradrenaline in orthostatic hypotension. Fed. Proc. 1963, 22, 389. 